\title{
Análise fitoquímica dos extratos hidroalcoólico da entrecasca e da folha de Pseudobombax marginatum (St. Hill) Rob.
}

Helaine Mirelli de Almeida* (Pós-graduanda no PPGCN na Universidade do Estado do Rio Grande do Norte - UERN);

Francisco Fábio M. Oliveira (Pós-graduando no PPGCN na Universidade do Estado do Rio Grande do Norte - UERN);

Dayseanne Araújo Falcão (Prof. a Ad. do DCB na Universidade do Estado do Rio Grande do Norte UERN).

*E-mail: helainemirelli@gmail.com

\section{Resumo:}

A Embiratanha, Pseudobombax marginatum, é uma planta medicinal amplamente utilizada na região Potiguar. Suas propriedades medicinais estão relacionadas principalmente a produção de metabólitos secundários. A identificação preliminar desses metabolitos é essencial para os estudos dos efeitos farmacológicos de plantas medicinais. Assim, o objetivo deste trabalho foi detectar os principais constituintes químicos dos extratos hidroalcoólicos da entrecasca e da folha de $P$. marginatum. O material vegetal foi coletado nos meses de fevereiro e maio de 2015, na FLONA - Assú, Rio Grande do Norte. Os extratos foram obtidos através da maceração com álcool 70\%. O estudo fitoquímico para a identificação de fenóis, taninos, antocianinas, antocianidinas, flavonoides, leucoantocianidinas, catequinas, flavanonas, alcaloides, saponinas, esteroides, triterpenoides, quinonas e antraquinonas, seguiu a metodologia descrita por Matos (1997). Ambos os extratos, entrecasca e folha, apresentaram compostos como fenóis, taninos, saponinas, esteroides livres, alcaloides e flavonoides. Todos esses compostos apresentam propriedades farmacológicas, citadas na literatura, que corroboram com o uso popular de $P$. marginatum. No entanto, mais estudos são necessários para legitimar o uso seguro desta planta medicinal.

Pallavras-chave:

Pseudobombax marginatum; prospecção fitoqímica; propriedades farmacológicas. 


\section{I ntrodução}

A espécie Pseudobombax marginatum (A.St.-Hil., Juss. \&Cambess.) A. Robyns é uma planta da família Malvaceae, subfamília Bombacoidea, vastamente encontrada no Nordeste brasileiro, sendo conhecida popularmente como embitaratanha, embiruçu, imbiratanha, paina-de-arbusto (DUARTE, 2006).

Devido a suas propriedades farmacológicas, é uma espécie amplamente utilizada na região Potiguar (PAULINO et al., 2011). O decocto e o macerado aquoso de sua casca e entrecasca é comumente utilizado para o tratamento de insônia, ulcéras, gastrites e inflamações e dores na coluna vertebral (AGRA et al., 2008; ROQUE; ROCHA; LOIOLA, 2010; PAULINO et al., 2012). No que diz respeito a estudos de prospecção fitoquímica e avaliação das propriedades farmacológicas de $P$. marginatum, tem-se uma literatura bastante escassa (CHAVES et al., 2013; PAIVA et al., 2013).

Atualmente, a fitoterapia tem sido uma alternativa para o tratamento de diversas doenças, devido às propriedades farmacológicas de extratos vegetais. Estas propriedades medicinais estão relacionadas principalmente a produção de metabólitos secundários pelos vegetais. O uso de plantas medicinais, no entanto, requer cuidados, pois estes compostos podem também ser nocivas aos organismos que delas se utilizam (MARQUES et al, 2003). Assim, uma das principais etapas dos estudos com plantas medicinais envolvem investigações fitoquímicas, que permite conhecer, de forma preliminar, a natureza das substâncias presentes (MACIEL et al., 2002).

O objetivo deste trabalho foi detectar a ausência ou a ocorrência de diversos constituintes químicos nos extratos hidroalcoólicos da entrecasca e da folha de P. marginatum.

\section{Metodologia}

\subsection{Coleta e produção dos extratos de $P$. marginatum}

A coleta da entrecasca e da folha de P. marginatum foi realizada nos meses de fevereiro e maio de 2015, na Floresta Nacional de Assú (Flona-Açu), Rio Grande do Norte. Foram coletados respectivamente 3,7 e 5,2 kg de peso fresco de entrecasca e de folha. As exsicatas foram identificadas e depositadas no Herbário Dárdano de Andrade Lima, Universidade Federal do Semi-Árido (UFERSA).

Para a obtenção do Extrato Hidroalcoólico da Entrecasca (EHE) e da Folha (EHF) de $P$. marginatum, o material vegetal foi seco em estufa de circulação de ar à uma temperatura de $40^{\circ} \mathrm{C}$ por 96 horas. Posteriormente, o material foi pesado, triturado e macerado com etanol a $70 \%$ sob agitação ocasional por um período de 9 dias, com renovação do liquido extrator a cada 3 dias. O liquido extraído passou por duas filtrações sob pressão reduzida e foi concentrado em banho-maria à $60^{\circ} \mathrm{C}$ para evaporação do etanol e da água e obtenção dos extratos sólidos brutos.

Depois de seco, os extratos tiveram sua massa medida para cálculo do rendimento de extrativos com relação ao peso da planta seca.

\subsection{Análise fitoquímica do EHE e EHF de $P$. marginatum}

Seguindo a metodologia de Matos (1997), o extrato foi submetido à análise fitoquímica qualitativa para detecção das principais classes de metabólitos. Para a identificação de fenóis, taninos, antocianinas, antocianidinas, flavonoides, leucoantocianidinas, catequinas, flavanonas, alcaloides, saponinas, esteroides, triterpenoides, quinonas e antraquinonass, os extratos foram solubilizados em água destilada ou em outros compostos de acordo com a especificidade de cada teste conforme descrito abaixo.

Para a analise de fenóis e taninos, adicionou gotas de cloreto férrico $\left(\mathrm{FeCl}_{3}\right)$ em um tubo de ensaio contendo $3 \mathrm{~mL}$ dos extratos solubilizados e agitou por alguns instantes. Para o branco utilizou um tubo com água destilada e FeCl3. A presença de fenóis foi determinada de acordo com o aparecimento da coloração indicada para cada substância quando o teste "branco" for negativo. Coloração variável entre o azul e o vermelho é indicativa da presença de fenóis. Precipitado escuro com tonalidade azul indica presença de taninos pirogálicos e a cor verde, a presença de taninos condensados ou catéquicos.

Na segunda análise, para antocianinas, antocianidas e flavonóides, utilizou três tubos de ensaio com $3 \mathrm{~mL}$ da amostra. Um tubo foi acidulado com $\mathrm{HCl} 1 \%$ até o pH 3, o segundo tubo alcalinizado com $\mathrm{NaOH} 5 \%$ até o pH 8,5 e o terceiro a pH 11. O aparecimento de mudança na coloração do material indica a presença de vários constituintes, de acordo com o quadro 1. 
Para leucoantocianidinas, catequinas e flavanonas, dois tubos de ensaio contendo $3 \mathrm{~mL}$ dos extratos tiveram seu $\mathrm{pH}$ modificados. O primeiro foi acidulado por adição de $\mathrm{HCl}$ até $\mathrm{pH}$ 1-3 e o outro alcalinizado com $\mathrm{NaOH}$ até $\mathrm{pH} 11$. Ambos foram aquecidos com o auxílio de uma lâmpada de álcool durante 2-3 minutos. O aparecimento ou intensificação de cor indica a presença de constituintes especificados no quadro 2 .

Quadro 1 - Indicativa da presença de constituintes para teste de antocianinas, antocianinas e flavonoides.

\begin{tabular}{|l|c|c|c|}
\hline \multirow{2}{*}{ Constituintes } & \multicolumn{3}{|c|}{ Cor do meio } \\
\cline { 2 - 4 } & $\mathbf{p H ~ 3}$ & $\mathbf{p H ~ 8 , 5}$ & $\boldsymbol{p H ~ 1 1}$ \\
\hline Antocianinas e antocianidinas & Vermelho & Lilás & Azul púrpura \\
\hline Flavonas, flavonóis e xantonas & --- & --- & Amarela \\
\hline Chalconas e auronas & Vermelho & --- & Vermelho \\
\hline Flavanonóis & --- & --- & Vermelho-Laranja \\
\hline
\end{tabular}

Fonte: Matos (1997).

Quadro 2 - Indicativa da presença de constituintes para teste de antocianinas, antocianinas e flavonoides.

\begin{tabular}{|l|c|c|c|}
\hline \multirow{2}{*}{ Constituintes } & \multicolumn{3}{|c|}{ Cor do meio } \\
\cline { 2 - 4 } & $\mathbf{p H ~ 3}$ & $\mathbf{p H ~ 8 , 5}$ & $\boldsymbol{p H ~ 1 1}$ \\
\hline Antocianinas e antocianidinas & Vermelho & Lilás & Azul púrpura \\
\hline Flavonas, flavonóis e xantonas & --- & --- & Amarela \\
\hline Chalconas e auronas & Vermelho & --- & Vermelho \\
\hline Flavanonóis & --- & --- & Vermelho-Laranja \\
\hline
\end{tabular}

Fonte: Matos (1997).

No teste para alcaloides, alguns miligramas do extrato seco foi dissolvido em $5 \mathrm{~mL}$ de solução de $\mathrm{HCl}$ a 5\%. A mistura foi filtrada e separada em três porções. A elas foram adicionadas respectivamente 3 gotas do reagente de Wagner, Mayer e Dragendorf. O aparecimento de turvação branca com os reativos de Wagner e Mayer, e de cor alaranjada com o reativo de Dragendorff indica a presença de alcaloides.

Para detectar a presença de saponinas, os extratos da entrecasca e da folha foram diluídos em $10 \mathrm{~mL}$ de água destilada. $\mathrm{O}$ tubo fechado foi agitado vigorosamente durante 2 minutos. A formação de uma cada de espuma persistente e abundante indica a positividade do teste.

Os testes para esteroides e triterpenoides foram realizados pela reação de Lieberman-Burchard, onde alguns miligramas dos extratos secos foram dissolvidos em $10 \mathrm{~mL}$ de Clorofórmio e filtrados posteriormente. Ao filtrado foi adicionado $1 \mathrm{~mL}$ de anidrido acético, agitando suavemente. Em seguida, adicionou cuidadosamente três gotas de ácido sulfúrico $\left(\mathrm{H}_{2} \mathrm{SO}_{4}\right)$ concentrado, agitando novamente. Cores que vão do azul evanescente, ao verde persistente indicam presença de esteroides livres, enquanto, do pardo ao vermelho indica triterpenoides pentacíclicos livres.

A reação direta de Bornträger foi usada para identificar a presença de quinonas e antraquinonas nos extratos. Uma pequena porção do extrato foi diluída em $5 \mathrm{~mL}$ de éter etílico, agitada suavemente por 2 minutos e filtrada. À solução etérea do extrato adicionou $2 \mathrm{~mL}$ de solução de hidróxido de amônio $\left(\mathrm{NH}_{4} \mathrm{OH}\right) 10 \%$, agitou suavemente e verificou o aparecimento de coloração rósea ou vermelha na fase aquosa, que indica reação positiva para quinonas e antraquinonas.

\section{Resultados e Discussão}

Com a extração hidroalcoólica com etanol 70\% obteve-se um rendimento de 10,9\% e 12,1\% de extrativos solúveis para o extrato da entrecasca e da folha, respectivamente. O rendimento obtido com a extração esteve dentro do previsto (SIMÕES, 2007).

As análises fitoquímicas fornecem informações importantes sobre a presença de metabolitos secundários em plantas. Segundo Matos (1997), a prospecção química de produtos naturais tem por objetivo registrar previamente os constituintes resultantes do metabolismo secundário dos seres vivos. Os resultados obtidos nos testes fitoquímicos para os extratos hidroalcoólico bruto da entrecasca e da folha de P. marginatum estão descritos no Quadro 3. Dentre as classes químicas identificadas, observa- 
se a presença de fenóis, taninos, saponinas, esteroides livres, alcaloides, bem como flavonoides e seus derivados para ambos os extratos. A presença de antocianinas, antocianidinas, leucoantocianidinas e quinonas não foi observada.

Quadro 3 - Prospecção qualitativa dos constituintes químicos de EHE e EHF de $P$. marginatum.

\begin{tabular}{|l|c|c|}
\hline Constituintes & EHE & EHF \\
\hline Fenóis & + & + \\
\hline Taninos e catequinas & + & + \\
\hline Antocianinas, antocianidinas e leucoantocianidinas & - & - \\
\hline Flavonóis, flavononóis, flavanonas e xantonas & + & + \\
\hline Chalconas e auronas & + & + \\
\hline Alcalóides & + & + \\
\hline Saponinas & + & + \\
\hline Esteroides livres & - & - \\
\hline Quinonas e antraquinonas & + & + \\
\hline
\end{tabular}

EHE = Extrato hidroalcoólico da entrecasca; EHF = Extrato hidroalcoólico da folha; (+) Presença; (-) Ausência.

A presença de fenóis, taninos, alcalóides, esteróides livres e algumas classes de flavonóides foram detectadas em extratos hidroalcoólicos da casca e entrecasca de P. marginatum de acordo com Chaves (2012) e Paiva et al. (2013). A literatura, não dispõe de trabalhos que apresentem dados fitoquímicos da folha de Embiratanha, No entanto, tem-se o registro de que a Barriguda (Ceiba glaziovii), planta que pertence a mesma subfamília, apresenta taninos catéquicos, flavonóis, alcalóides e traços de antocianinas, antocianidinas e saponinas nas folhas (LEAL et al., 2011).

A ocorrência de resultados negativos não significa a ausência dos grupos químicos na planta. Alguns fatores, como o solvente utilizado na fase de extração, as baixas concentrações das substancias nos tecidos vegetais ou até mesmo a interferência de outros constituintes na formação das cores durante os testes podem inviabilizar a detecção por reações qualitativas. Menezes et al. (2015) avaliou a concentração de antocianinas presentes em diferentes partes (galhos, cascas, raízes e flores) de $P$. marginatum. Os resultados obtidos constataram que as concentrações de antocianinas nesta planta não apresentaram resultados muito significativos. Dentre os membros estudados, os caules e galhos apresentaram os resultados mais relevantes para o estudo em questão, com valores de antocianinas de 0,49 e $0,38 \mathrm{mg} / 100 \mathrm{~g}$, respectivamente.

Os compostos fenólicos abrangem um extenso grupo de substâncias que possuem um anel aromático contendo pelo menos uma hidroxila. Estes compostos incluem: fenóis simples e glicosilados, cumarinas, ligninas, flavonóides e quinonas (STANGARLIN et al, 2011). Dentre os compostos fenólicos, destacam-se os flavonoides, presentes em P. marginatum.

Nos vegetais estes compostos apresentam funções principalmente relacionadas à pigmentação, ação protetora às radiações, além de propriedades antioxidantes de proteção ao metabolismo vegetal. Os flavonoides são considerados potentes antioxidantes naturais, devido aos grupos hidroxila ligados à estrutura do anel aromático (ALMEIDA et al., 2006). Possuem ainda atividade anti-inflamatória, antialérgica, antitrombótica e vasoprotetora, além de ação protetora da mucosa gástrica (DEGÁSPARI; WASZCZYNSKYJ, 2004; PAIVA et al. 2013).

Taninos são substâncias complexas presentes em inúmeros vegetais, encontrados geralmente nas folhas, frutos e sementes. Apresenta efeito sobre o processo de cicatrização de feridas, queimaduras, úlceras, que está diretamente relacionado a formação do complexos tanino/proteína, que gera uma camada protetora sobre a área lesada (SIMÕES, 2007). Os taninos também apresentam potente ação antimicrobiana e antifúngica, efeito este verificado por Chaves et al. (2013) para o extrato alcoólico da casca de $P$. marginatum. Sabe-se ainda que os taninos são usados tradicionalmente no tratamento de diversas doenças como diarreia, hipertensão, processos inflamatórios em geral e outros (SIMÕES, 2007).

As saponinas espumídicas, presentes nos extratos de $P$. marginatum, são compostos não nitrogenados que se dissolvem em água originando soluções espumantes. Assim, apresentam a propriedade de emulsionar óleos e de produzirem hemólise. Suas atividades terapêuticas estão 
relacionadas às propriedades diuréticas, digestivas, antiespasmódicas e como fonte de vitamina P. Essas biomoléculas também possuem potencial anti-inflamatório, como exemplo a glicirrizina isolada da Glycyrrhiza glabra, que age na inibição de enzimas catabolizadoras de prostaglandinas, que provoca o aumento de prostaglandinas endógenas que participam dos processos anti-inflamatórios (BIGHETTI; ANTÔNIO; CARVALHO, 2002; SIMÕES, 2007).

Os esteroides são formados a partir dos triterpenos por meio de descarboxilações. Dentre suas principais atividades está a anti-inflamatória e a analgésica (RODRIGUES et al., 2010), além da atividade antitumoral (SALVADOR et al., 2013). Análogos sintéticos de esteroides, como por exemplo, a Dexametasona, são muito usados em tratamentos quimioterápicos. Eles exercem efeitos antiproliferativos em vários tipos de células cancerígenas, como as células K56, de leucemia humana, as HT-29, de cancro do cólon e as M4B, de melanoma (MINORICS et al., 2011).

\section{Conclusão}

A prospecção fitoquímica dos extratos hidroalcoólico da entrecasca e folha de $P$. marginatum detectaram composto fenólicos, como fenóis, taninos e flavonoides, além de xantonas, alcaloides, saponinas e esteroides livres. Outros estudos são necessários para validar o uso seguro desta planta medicinal.

\section{Phytochemical analisys of the inner bark and leaf hydroalcoholic extract of Pseudobombax marginatum (St. Hill) Rob.}

Albstract: Embiratanha, Pseudobombax marginatum, is a medicinal plant widely used at Brasilian northeast Potiguar region. Its medicinal properties are associated with the secondary metabolites produced by it. This preliminar knowledge this one is essential for the pharmacological effects studies of medicinal plants. Thus, the aim of this paper was to detect the main chemical constituents in the inner bark and leaf hydroalcoholic extract of P. marginatum. The plant material was collected in February and May of 2015, on FLONA - Assú, Rio Grande do Norte. The extracts were obtained through maceration with alcohol 70\%. The phytochemical analysis of phenols, tannins, anthocyanins, anthocyanins, flavonoids, leucoanthocyanidins, catechins, flavanones, alkaloids, saponins, steroids, triterpenoids, quinones and anthraquinones, followed the methodology described by Matos (1997). Both extracts, inner bark and leaf, showed phenols, tannins, saponins, steroids e flavonoids compounds. All these compounds show pharmacological properties, reported in the literature, that corroborate the popular use of $P$. marginatum. However, more studies are required to justify the safe use this medicinal plant.

Keywords: Pseudobombax marginatum; phytochemical screening; pharmacological properties.

\section{Referências bibliográficas}

DUARTE, Marília Cristina. Diversidade de Bombacaceae Kunth no estado de São Paulo. 2006. 112 f. Dissertação (Mestrado) - Biodiversidade Vegetal e Meio Ambiente, Instituto de Botânica da Secretaria do Meio Ambiente, São Paulo, 2006.

PAULINO, Renan. da C. et al. Medicinal plants at the sítio do Gois, Apodi, Rio Grande do Norte state, Brazil. Brazilian Journal of Pharmacognosy. n. 22, p. 29-30, 2012.

PAULINO, Renan da C. et al. Riqueza e importância das plantas medicinais do Rio Grande do Norte. Revista de Biologia e Ciências da Terra. v. 11, n. 1, p. 157-168, 2011. 
AGRA, Maria de F. et al. Survey of medicinal plants used in the region Northeast of Brazil. Brazilian Journal of Pharmacognosy, v.18, n.3, p. 472-508, 2008.

ROQUE, Alan de A.; ROCHA, Renato M.; LOIOLA, Maria I. B. Uso e diversidade de plantas medicinais da Caatinga na comunidade rural de Laginhas, município de Caicó, Rio Grande do Norte (Nordeste do Brasil). Rev. Bras. Pl. Med., Botucatu, v.12, n.1, p.31-42, 2010.

CHAVES, Thiago P. et al. Seasonal variation in the production of secondary metabolites and antimicrobial activity of two plant species used in Brazilian traditional medicine. African Journal of Biotechnology. v. 12 (8), p. 847-853, 2013.

PAIVA, Dayanne C. C. et al. Anti-inflammatory and antinociceptive effects of hydroalcoholic extract from Pseudobombax marginatum inner bark from caatinga potiguar. Journal Ethnopharmacology. v. 149 (2), p. 416-421. 2013.

MACIEL, Maria A. M.; PINTO, Angelo C.; VEIGA JR, Valdir F. Plantas medicinais: a necessidade de estudos multidisciplinares. Química Nova, São Paulo, v. 25, n. 3, p. 429-438, 2002.

MARQUES, Regina C. P. et al. Evaluation of the mutagenic potential of yangambin and of the hydroalcoholic extract of Ocotea duckei by the Ames test. Mutat. Res., vol. 536, no. 1-2, p. 117-120, 2003.

MATOS, Francisco J. A. Introdução à fitoquímica experimental. Fortaleza: UFC Edições, 1997.

SIMÕES, Claudia M. O. (org.). Farmacognosia: da planta ao medicamento. 6 ed. Porto Alegre: Editora da UFRGS, 2007.

CHAVES, Thiago P. Variação sazonal na produção de metabólitos secundários e na atividade antimicrobiana de espécies vegetais do semiárido brasileiro. 77p. Dissertação (mestrado) - Ciência e Tecnologia Ambiental, Universidade Estadual da Paraíba, Campina Grande-PB, 2012.

LEAL, André J. B. et al. Estudo Fitoquímico Antimicrobiano de Ceiba glaziovii Kuntze K. Schum. Biofar. v.5, n. 1, 2011.

STANGARLIN, J. R. et al. A defesa vegetal contra fitopatógenos. Scientia Agraria Paranaenis. v. 10, n. 1, p 18-46, 2011.

MENEZES, M. A. G. et al. Quantificação de antocianinas dos extratos de embiratanha (Pseudobombax marginatum). HOLOS, Ano 31, v. 1, p. 30-35, 2015.

ALMEIDA, Joaquim M. D. et al. Avaliação da atividade antioxidante utilizando sistema ßcaroteno/ácido linoléico e método de sequestro de radicais DPPH. Ciência e Tecnologia de Alimentos, Campinas, v. 26, n. 2, p. 446-452, abri. -jun. 2006.

DEGÁSPARI, Claudia H.; WASZCZYNSKYJ, Nina. Propriedades antioxidantes de compostos fenólicos. Visão Acadêmica, Curitiba, v. 5, n. 1, p. 33-40, Jan.- Jun., 2004.

MINORICS, Renata et al. Antiproliferative effects of some novel synthetic solanidine analogs on HL60 human leukemia cells in vitro. Steroids, 76, 156-162, 2011.

SALVADOR, Jorge A. R. et al. Anti câncer steroids: linking natural and semi-synthetic compounds. Natural Product Reports 30, 205 - 376, 2013.

BIGHETTI, Aparecida E.; ANTÔNIO, Márcia A.; CARVALHO, João E. Regulação e modulação da secreção gástrica. Revista de Ciências Médicas. v. 11. p. 55-60. 2002. 
RODRIGUES, Klinger A. F. et al. Prospeç̧ão fitoquímica e atividade moluscicida de folhas de Momordica charantia L. Cadernos de Pesquisa. v. 17,p. 69-76, 2010. 